CASOS CLINICOS

Rev. Chll. Podlatr. 64 (1); 32-35, 1993

\title{
Talla baja por resistencia a la hormona de crecimiento
}

\author{
Martha Eggers M.1; Sofía Aros A. ${ }^{2}$; Pamela Pérez O. ${ }^{3}$; \\ Fernando Cassorla G. ${ }^{1}$
}

\section{Growth hormone resistance}

Growth relardation can be due to inodequate growth hormone secretion or lack of biological response to its eftects. The dinical picture is quile similar in both conditions. Growth hormone exerts its biological effects through cellular receplors which, if absent, con lead to growth relardation. We present a 14 year 7 monih old boy with exlreme shorl stakure theight $95 \mathrm{~cm}$ ), centripelal obesity, small hands and feets, micropenis, and immaluie focies, which suggested growth homone deficiency. His sewm growth hormone concenirations were elevated, and his somotomedin. was decreased. The boy wos liealed with growth hormone and he did not show any biochemical or clinical response, suggesting that he has growth homone resistance.

[Key words: growth disorders, growth hormone, somaloliopin, resistance.)

El proceso normal de crecimiento está regulado por varios elementos. Entre los factores endocrinos destaca la hormona de crecimiento, cuya secreción por la hipofisis depende fundamentalmente de la interacción entre un factor estimulador y otro inhibidor producidos por el hipotálamo. La hormona del crecimiento ejerce su acción mediante su union a receptores específicos localizados en las células blanco, desencadenando una serie de respuestas metabólicas. Entre éstas destaca la produccion de un grupo de proteínas conocidas como factores de crecimiento semejantes a la insulina. Uno de ellos, la somatomedina-C (IGF1), parece ser el principal responsable de la estimulación del crecimiento lineal del esqueleto.

Una alteración en cualquier etapa de esta secuencia metabólica puede conducir a un retraso de crecimiento. Especificamente, se ha descrito un grupo de niños que tienen un déficit $\mathrm{cn}$ los

1. Hospizal Clínico San Borja-Arriarán. Instituto de Investigaciones Matemo Infantil (IDIM).

2. Becadode Pedintría. Hospital Clinieo San Borja-Artiaran. Facultad de Medicina Universidad de Chile.

3. Becado de Pedialnía. Hospital San Juan de Dios. Facultad de Medicina Universidad de Chile. receptores de la somatotropina. Esto produce resistencia periférica a la acción de ella con un cuadro clínico muy similar al del déficit clásico de producción de la misma.

En este articulo describimos un niffo con una talla extremadamente baja para su edad debido a una resistencia periférica a la hormona de crecimiento. Este paciente constituye el primer caso de este síndrome descrito en Chile.

\section{Caso Clínico}

Niño enviado desde Puerto Montt a nuestro Hospital a los 14 años y 7 meses por retraso de crecimiento severo desde los primenos meses de vida. Nacido en parto de témino con fórceps, peso de nacimiento $3,2 \mathrm{~kg}$ se desconocen la talla y otros antecedentes perinatales. Padres consanguíneos (primos-hemanos), talla matema $158 \mathrm{~cm}$ y palema $160 \mathrm{~cm}$. ambos sanos. Cinco hernanos sanos con talla nomal baja (entre percentiles 3 y 25 de tablas NCHS). No hay parientes de talla inferior al peroentil 3 ni antecedentes de afecciones endocrinas en la familia. Sufrió episodios sugerentes de hipoglicemia en los primeros años de vida. Criptorquidis bílaleral operada a los 13 años y enfemedad de Perthes unilateral diagresticada los 12 años, tratada con reposo. sin mayor repercusión clínica. Desartollo psicomotor adecuado, rendimiento escolar aceptable para su edad. A la edad de 14 años y 7 meses la talla era $95 \mathrm{~cm}$ (percentil 50 para 3 años) y el peso $15,7 \mathrm{~kg}$, proportionado, con obesidad troncal, facies con frente prominente, puente nasal bajo $y$ 
nariz pequeña, micropene ( $2 \mathrm{~cm}$, testes de $1,5 \mathrm{cc}$ de volumen, ubicados en el escroto (figuras 1 y 2 ). Gíticernia en ayunas $60 \mathrm{mg} / \mathrm{dl}$; proteinemis $6,2 \mathrm{~g} / \mathrm{dl}$; 2lbuminemia $4,1 \mathrm{~g} /$ $\mathrm{dl}$; calcemia $9.2 \mathrm{mg} / \mathrm{dl}$; fosfemia $3.8 \mathrm{mg} / \mathrm{dl}_{\text {; fosfalasas }}$ alcalinas $218 \mathrm{~L} /$; creatininenia $0,2 \mathrm{mg} / \mathrm{dl}$; colesterolemia $233 \mathrm{mg} / \mathrm{dl}$; triglicéridos $87 \mathrm{mg} / \mathrm{dl}$. Edad osea muy retrasada 7 años. Radiografía de cráneo: aumento del diámetro biparietal y silla turca nomal. Estudio endocrinologico (tabla); las pruebas de insulina y clonidina mostraron valores basales altos de homona de crecimiento que no aumentaron cn foma significativa con el estíntulo. Conisol y hormonas iroídeas normales. Gonadotrofinas caractetísticas de desarrollo puberal incipiente. Somatomedina.C bseal de $0,44 \mathrm{U} / \mathrm{m}$ l (valor bajo para edad ósea y edad cronológica), sin modificaciones después del tratamiento con hormona de crecimiento a una dosis de $0,1 \mathrm{U} / \mathbf{k g} /$ día por 5 dias $(0,41$ $\mathrm{L} / \mathrm{ml})$.

Se indics tratamiento por 3 meses con hormona de crecimiento biosintética $0,1 \mathrm{U} \times \mathbf{~ k g} \times$ día subcutánea sin observarse cambio en su velocidad de crecimiento. Presentó pubertad cspontánea a los 15 años y 6 meses con progresión normal de los cafacteres sexuales secundarios. A los 18 años su talla es $109 \mathrm{~cm}$, pesa $22,5 \mathrm{~kg}$, el volumen de los testes es $17 \mathrm{ec}$, velto pubiano Tanner 2 , edad bsea 13 años y 6 meses.

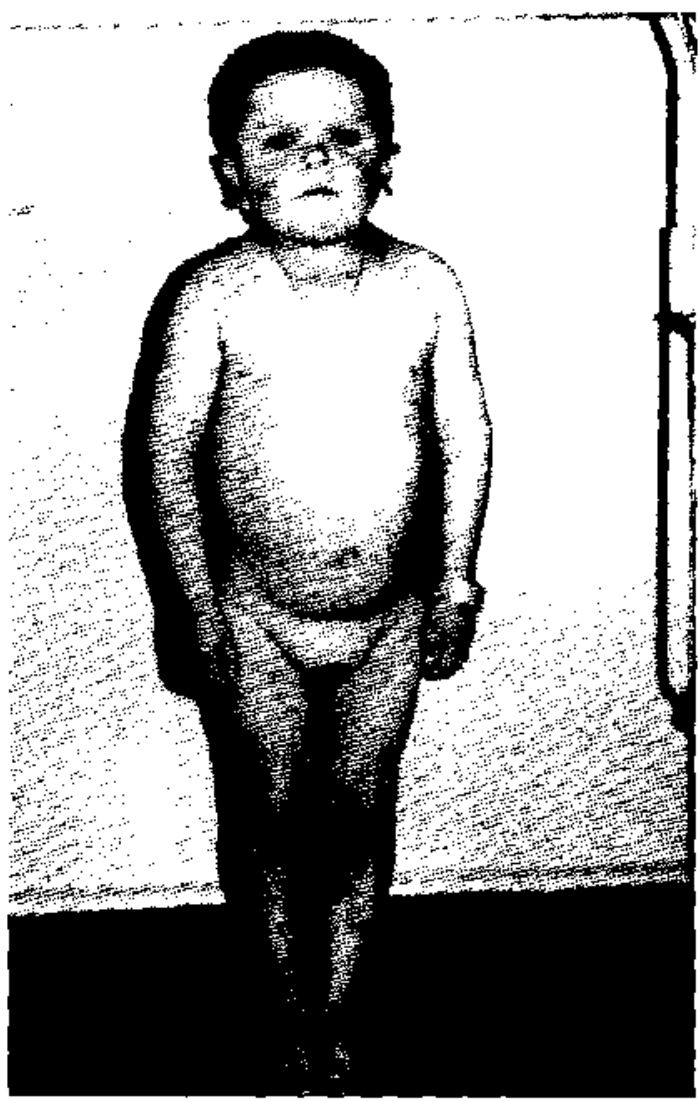

Figura 1: Paciente de 14 arios y 7 meses de edad con resisten. cia a le hormotia de crecirniento. Talla $95 \mathrm{~cm}$ y peso $15,7 \mathrm{~kg}$.

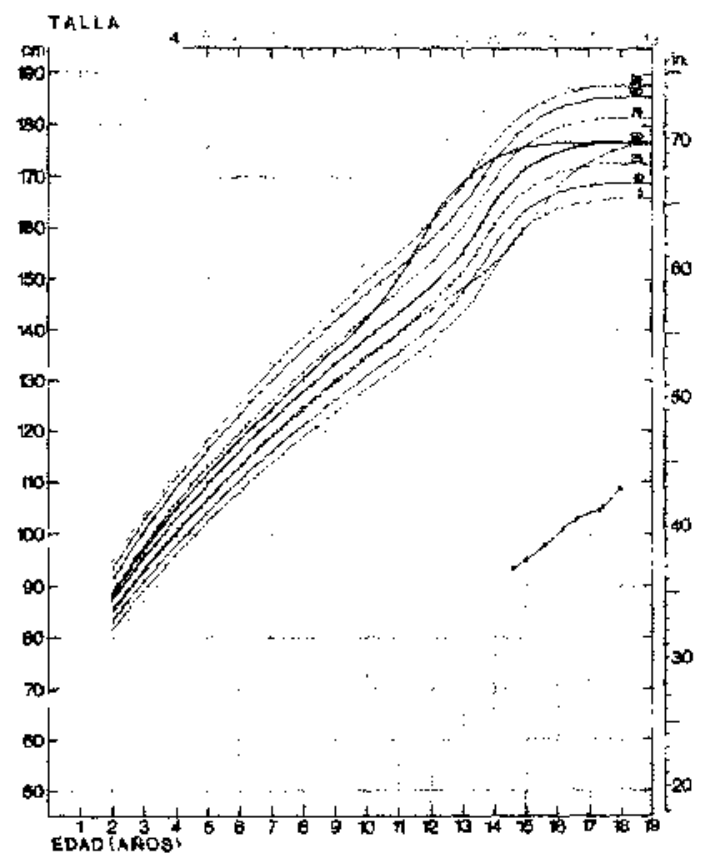

Figura 2: Curva de crecimiento.

\section{Comentario}

Laron y colaboradores en 1966 , en lsrael ${ }^{1}$ fueron los primeros en describir un cuadro clínico similar al clásicamente descrito en pacientes con deficiencia de hormona de crecimiento, pero con niveles plasmáticos de ésta muy aumentados, lo que sugirió una resistencia a la acción de dicha hormona. Sus características más relevantes son talla baja, facies infantil con frente prominente, manos, pies y nariz pequeños, obesidad centripeta, voz aguda y episodios de hipoglicemia durante la infancia. Posteriormente, se han descrito pacientes de este tipo en otras regiones, entre las cuales destaca una población đe Ecuador reportada recientementc ${ }^{2}$, con un cuadro clínico muy similar al descrito por Laron, salvo por un franco predominio en mujeres.

Para que un niño crezca normalmente, son indispensables la secreción adecuada -por la hipófisis de hormona de crecimiento y receptores tisulares para ella. El gen del receptor para somatotropina se localiza en el cromosoma 5 y su estructura ha sido caracterizada en células hepáticas. Se ha demostrado en pacientes con síndrome de Laron deleciones parciales en este gen, variables de uno a otro caso, lo que demues- 
Tabla 1

Evaluación endocrinologica

\begin{tabular}{|c|c|c|c|c|c|c|c|}
\hline \multirow[b]{2}{*}{ Tiempo } & \multirow[b]{2}{*}{$(\min )$} & \multicolumn{6}{|c|}{ Prueba de insulina $(0,05 \mu / \mathrm{kg})$} \\
\hline & & 0 & 15 & 30 & 60 & 90 & 120 \\
\hline Glicemia & $(\mathrm{mg} / \mathrm{dl})$ & 72 & 18 & 45 & 65 & 74 & 68 \\
\hline GH & $(\mathrm{ng} / \mathrm{ml})$ & 15 & 15 & 14 & 16 & 8 & 4 \\
\hline \multirow[t]{2}{*}{ Contisol } & $(\mathrm{ng} / \mathrm{ml})$ & 240 & - & 210 & 320 & - & - \\
\hline & & \multicolumn{6}{|c|}{ Prueba de clonidina (100 $\left.\mathrm{\mu g} / \mathrm{m}^{2}\right)$} \\
\hline \multirow{3}{*}{$\begin{array}{l}\text { Tiempo } \\
\mathrm{GH}\end{array}$} & (min) & 0 & 60 & 90 & & & \\
\hline & $(\mathrm{ng} / \mathrm{ml})$ & 30 & 29,5 & 24,4 & & & \\
\hline & & \multicolumn{6}{|c|}{ Pruebre de LH.RH } \\
\hline Tiempo & $(\min )$ & 0 & 15 & 30 & 60 & 90 & 120 \\
\hline $\mathrm{FSH}$ & (mUL/ml) & 0.9 & 4,2 & 0.1 & 0,1 & 0,1 & 0,8 \\
\hline LH & (mUI/ml) & 4.2 & 14 & 21 & 14,5 & 8 & 6,2 \\
\hline
\end{tabular}

\section{GH: somatotropina.}

LH: hormona luleinizante.

T3: trijodotironina.
FSH: homona folículo estimulante.

TSH: tirotropina.

T4: tetraiodotironina. tra el defecto genético es heterogéneo ${ }^{3,4}$. Al estar alterado este gen, la hormona de crecimiento no ejerce su efecto en los tejidos, lo que conduce a deficiente producción de somatomedina-C. Esta última es uno de los factores que regulan la liberación de hormona de crecimiento por la hipófisis, lo que realiza a través de un mecanismo de retroalimentación negativa, explicándose así, en el síndrome de Laron, las altas concentraciones de hormona de crecimiento.

En condiciones normales la hormona de crecimiento circula en la sangre junto a una proteína transportadora de alta afinidad, otra de baja afinidad y también como hormona libres. 6 . La proteina de alta afinidad ha sido estudiada y corresponde a la porción extracelular del receptor de hormona de crecimiento ${ }^{7,8}$, Por lo tanto, la concentración plasmática de esta proteína transportadora de alta afinidad parece reflejar el número de receptores tisulares para dicha hormona.

Nuestro paciente presenta todas las caracteristicas clínicas descritas por Laron. El estudio de laboratorio con glicemia basal baja, concentraciones plasmáticas altas de hormona de crecimiento, somatomedina-C baja y falta de respuesth al tratamiento con hormona de crecimiento biosintética, son concordantes con este diagnóstico. La consanguinidad de los padres es compa- tible con la herencia autosomica recesiva de este sindrome. Debe mencionarse que un cuadro similar al descrito en este paciente, puede observarse en la desnutrición severa. En este caso las concentraciones de hormona de crecimiento pueden ser altas y se asocian a tasas bajas de somatomedina-C, lo que corresponde a una respuesta adapiativa del organismo ante la desnutrición. El buen estado nutricional de nuestro paciente excluye esta posibilidad.

El enanismo de Laron es una condición de retardo severo del crecimiento, caracterizado por disminución en la concentración de proteína transportadora de alta afjnidad y de receptores de hormona de crecimiento. Otras poblaciones con retraso severo del crecimiento exhiben formas distintas de resistencia a dicha hormona, entre los cuales cabe destacar a los pigmeos africanos ${ }^{5}$. Estos individuos lienen concentraciones séricas normales de somatotropina y tasas bajas de somatomedina-C, que no tienden a aumentar durante la adolescencia como en los individuos normales. Esto sugiere que los pigmeos tienen una deficiencia en la regulación, y no en la estructura de los receptores de hormona de crecimiento.

El tratamiento con somatomedina-C es el más promisorio para los pacientes con resistencia 
periférica a la hormona de crecimiento ${ }^{10}$. Recientemente se ha demostrado que su administración durante un período breve produce efectos metabólicos significativos en pacientes con síndrome de Laron. Queda por demostrar si el tratamiento prolongado podrá aumentar la velocidad de crecimiento de ellos.

\section{Resumen}

El retraso de crecimiento de un niño por alteraciones en la hormona de crecimiento puede producirse por déficit en su producción o por falta de respuesta a su efecto. Ambos grupos de niốos tienen características clinicas bastante similares. La hormona de cracimiento ejerce su efecto biologico a través de receptores tisulares, y si éstos están alterados se producirá un cuadro de resistencia periférica a dicha homona. Présentamos un niffo que consultó a los 14 af́os y 7 meses de edad por retraso severo del crecimiento, con talla de $95 \mathrm{~cm}$, obesidad centripeta, manos y pies pequeños, micropene y facies infantil, características sugerentes de un déficit de hormona de crecimiento. El estudio de laboratorio mostró concentraciones plasmáticas elevadas de hormona de crecimiento elevados y disminución de las de somatomedina-C. El paciente fue tratado con hormona de crecimiento biosintética, sin respuesta bioquímica ni clínica, lo que sugiere resistencia periférica a la acción de la somatorropina.

(Palabras clave: crecimiento, retardo, somatotropina, hormona de crecimiento, resistencia.)

\section{Referencias}

I. Laron $Z$, Perizelan A, Mannheimer S.: Genetic piruitary dwarfism with high serum concentration of growth hormone, a new inbort error of metabolism? Isr I Med Sci 1966; 2: 152-155.

2. Rosenbloom A, Guevara $J$, Rosenfeld $R$, Fielder $P$ : The litue women of Loja-Growth homone-receptor deficiency in an inbred population of southem Ecuador. N Engl J Med 1990; 323: 1367+1374.

3. Dodowski P, Leung D, Meacham L et al.: Characterization of the human srowth hormone receptor gene and demonstration of a partial gene deletion in two patients with Laron-type dwarfism. Proc Natl Acad Sti USA. 1989; 86: 8083-8087.

4. Amselem S, Duquesnay Ph: Laron dwarfism and mutations of the growlh hormone-receptor gene. $\mathrm{N}$ Engl J Med 1989; 321: 989-995.

5. Baumann G, Shaw M, Merimez T: Low levels of high affinity growth homone-binding protein in African pygmies. N Engl J Med 1989; 320: 1705-1709.

6. Boumann G. Stolar M, Ambum K, Barsano CP, De Vries B. A specific growth hormone-binding protein in humat plasma: Initial characterization. I Clin Endocrinal Metab 1986; 62: 134-141.

7. Leung D. Spercer A. Cachianes $G$ et al.: Growh hormone receptor and senum biading prolein: purification, cloning and expression. Nature 1987; 330: 537-543.

8. Bauman $G$, Show M. Brumbaugh $R, S$ chwariz $J$ : Short stature and decreased serum growh hormone-binding protein in the Mountain OK People of Papua New Guinea. I Clin Endocrinol Metab 1991: 72: 1346-1349.

9. Schaff-Blass $E_{1}$ Burstein $S$, Rosenjield R: Advances in diagnostic and Ireatment of short stature, with special reference to the role of growth hormone. J Pedialr $1984 ; 104: 801-813$.

10. Wallser J. Ginalska-Melinowske M, Romer $T_{1}$ Pucil. owsta $J$, Underwood $L$ : Effects of the infusion of insulin-like growth factor in a child with growl hormone insensitivity syndrome (Laron dwarsfism). N Eng1 J Med 1991: 324: 1483-1488. 